Tiempo de cambios, tiempo de tradición. La métrica de Antonio Colinas en su tiempo

\title{
TIEMPO DE CAMBIOS, TIEMPO DE TRADICIÓN. LA MÉTRICA DE ANTONIO COLINAS EN SU TIEMPO
}

\author{
Clara Isabel MARTÍNEZ CANTÓN \\ UNED \\ cimartinez@flog.uned.es
}

ntonio Colinas (La Bañeza, León, 1946) es ya un referente en la poesía española actual. Su
larga trayectoria se ha visto reconocida con varios premios, incluido el Premio Nacional de
Literatura en 1982 y el premio Reina Sofía de poesía Iberoamericana en 2016 . El autor se ha abierto camino en el mundo literario a través de un tratamiento muy personal de la poesía, alejado de las tendencias predominantes y las modas pasajeras, así como centrado en la búsqueda de un lenguaje propio, de una poética donde la meditación y la experiencia personal son la base para un conocimiento de carácter universal.

Muchas han sido las aproximaciones al estudio de su obra poética. Martínez Fernández, al que se ofrece este homenaje ${ }^{1}$, ha sido uno de sus estudiosos más serios y más asiduos (Martínez Fernández, 1988, 1990, 1997, 1998, 2004a, 2004b, 2008a, 2008b, 2009, 2010, 2012, 2014), y la nómina de críticos y académicos que han estudiado su obra es demasiado amplia para ser recogida aquí. Desde el terreno de la métrica también le ha dedicado artículos Martínez Fernández, como el que analizaba los ajustes métricos en Noche más allá de la noche (2005), o el realizado en colaboración con la que escribe el artículo sobre el poema «Oscuro oboe de bruma» (Martínez Fernández y Martínez Cantón, 2007). La métrica de su poesía ha sido el tema principal de dos de mis publicaciones (Martínez Cantón, 2011 y 2012).

En el presente estudios se propone de nuevo un acercamiento a la métrica de Antonio Colinas desde un enfoque comparatista. Se busca anclar la poesía del autor en su tiempo, comprobando su adscripción o no a las tendencias de la época. Para ello partimos de los trabajos que han estudiado la métrica de la poesía desde los años 70 hasta nuestros días, y mediante un estudio exhaustivo de los poemarios del autor se aplica una perspectiva comparativa.

La métrica estudia cómo el uso de ciertos elementos produce el ritmo poemático. Sin embargo no es un sistema aislado, cobra también significado en su seguimiento o transgresión por parte de los

\footnotetext{
${ }^{1}$ Escribo este estudio como homenaje a José Enrique Martínez Fernández, mi modelo, mi maestro, mi guía, mi padre. Poco se puede dar a quien me ha dado tanto, excepto, tal vez, estas palabras.
} 
poetas de unos patrones tradicionales, y de los patrones que se encuentran en boga en su época. Los poetas deciden retomar, variar o renovar tales esquemas métricos, y estas decisiones declaran en cierta medida su intención de establecerse o no dentro de un movimiento determinado o de una tradición poética concreta.

Con este artículo se quiere abordar la relación, en el terreno de la métrica, de la obra poética de Antonio Colinas con la de otros autores contemporáneos.

\section{Antonio Colinas y la métrica de la poesía española de los últimos treinta años}

Navarro Tomás adelantaba en su Métrica española, refiriéndose a la frecuencia de uso en la poesía española de la versificación regular y libre, que en el futuro (el libro se publica por primera vez en 1956) «se acentuará probablemente el equilibrio ya iniciado entre la versificación libre y la métrica regular» (1991: 50). En los últimos años hemos asistido a una normalización del versolibrismo y a una recuperación de la métrica regular en un mismo tiempo, e incluso dentro de la obra de un mismo autor.

Colinas publica sus dos primeras obras, Poemas de la tierra y la sangre y Preludios a una noche total en 1969. Por ello principalmente, aunque también debido a otras afinidades, se le ha considerado dentro del grupo de los Novísimos, que quedó bautizado de esta manera después de la publicación de la famosa antología Nueve Novísimos poetas españoles, compilada por J.M. Castellet y que vio la luz por primera vez en 1970. Entre los autores antologados no se encuentra, sin embargo, Antonio Colinas. Castellet señala en el prólogo como rasgo del grupo «la libertad formal», la falta de «preocupación normativa» (2001: 41), es decir, la tendencia a no seguir los cánones establecidos por la métrica tradicional o, mejor, métrica regular. Precisamente ésta es quizás la característica en la que el poeta leonés más se aleja de este grupo, y la que más nos interesa en este trabajo. No obstante, una mirada más profunda al panorama poético de estos años nos descubre que tanto poetas que aparecían en la antología, como Gimferrer y Carnero, como muchos otros entre los que se incluiría a Antonio Colinas, Antonio Carvajal, etc., sí hacen uso de patrones métricos regulares, inscritos en la tradición hispánica, muchas veces renovándola, y basan incluso su verso libre en ella (hay una marcada tendencia hacia la silva libre endecasilábica). Dice Utrera Torremocha al respecto, haciendo hincapié en la importancia en estos años de la métrica tradicional:

Algunos poetas Novísimos evolucionaron por sí mismos hacia formas más regulares desde finales de la década de los setenta. Además, una buena parte de la poesía versolibrista hispánica adapta el modelo bastante conservador de la silva libre impar. Obras como las de Claudio Rodríguez, Ángel González, José Ángel Valente, Antonio Carvajal o Luis Alberto de Cuenca, por ejemplo, se insertan plenamente en los cánones rítmicos tradicionales del verso, según se aprecia en el predominio existente del verso blanco o de rimo endecasilábico $[\ldots]$

En las últimas generaciones se aprecia un considerable abandono del verso libre arrítmico y prosaico (2001: 168-169).

La ruptura con la métrica tradicional se va dejando atrás. Antonio Colinas es, sin embargo, el ejemplo de la evolución inversa. Una poética que parte de una absoluta tradicionalidad y regularidad en sus primeras obras para llegar a una métrica con mayores libertades. 
En la evolución métrica que traza Utrera Torremocha (2001) de la poesía del último siglo se ve un paso desde una métrica más libre en el grupo de los Novísimos a una vuelta al clasicismo en los años ochenta. Este tipo de métrica que presenta para la década de los ochenta es, quizás, la que mejor describe la obra de Colinas, que se podría considerar entonces casi un precursor: «En general, los poetas que se incluyen en este retorno a la tradición clásica suelen emplear versos de factura tradicional, como el endecasílabo o el alejandrino y sus combinaciones» (2001: 175). La autora habla también de una vuelta en esta época a las composiciones estróficas y formas tradicionales, como el soneto o el serventesio. Esta no es, sin embargo, una característica del poeta bañezano, que parece reacio a componer en estrofas, primando siempre la libertad de las series de versos. No obstante, son precisamente sonetos y serventesios algunas de las pocas formas tradicionales utilizadas por el autor a lo largo de su obra poética.

El trabajo de Utrera Torremocha presenta además un interesante estudio (2001: 281-315) que aborda «El verso libre en la poesía española de los últimos treinta años» basado en la consulta de cuatro antologías $^{2}$ en dos de las cuales — la editada por García Martín, Treinta años de poesía española: (1975-1995), y la de Visor titulada El último tercio de siglo - se recogen composiciones de Antonio Colinas. La autora repasa el número de autores de los que se recogen poemas en verso libre en cada antología. Los resultados son los siguientes:

En las dos antologías de más amplio espectro, la consultada de Visor y la de García Martín la presencia de los poetas que se sirven del verso libre es importante. En la de García Martín, de gusto más clásico, algo más de la mitad de los autores - 12 de 23 - escriben algunos poemas en verso libre, aunque en la gran mayoría de los casos se trata sólo de un verso libre atenuado, es decir, fundamentado en claros ritmos de carácter endecasilábico que se rompen con más o menos frecuencia.

En la antología de Visor la proporción de los poetas que emplean verso libre, junto al regular, es mayor: supone tres cuartas partes del total -21 sobre 28 - El verso libre arrítmico, además, es más frecuente que en la antología anterior.

De los 24 poetas de la selección de García-Posada sólo una tercera parte ha usado el verso libre y, entre ellos, algo más de la mitad de ese tercio se expresa a través del versolibrismo arrítmico.

Por último, en la antología de Villena, defensor, como se ha visto antes, de los ritmos armónicamente libres y contra el tradicionalismo métrico, la mitad de los diez poetas antologados emplea el verso libre, pero sólo tres de ellos, es decir, algo menos de esa mitad, componen sus textos en un verso libre verdaderamente arrítmico. (Utrera Torremocha, 2001: 289).

Los poemas de Antonio Colinas que aparecen en las dos antologías que antes hemos señalado son en su mayoría regulares y, los menos, se basan en ese verso libre atenuado al que hace referencia la autora. Según los datos que se manejan, parece que el número de poetas que cultivan única o generalmente el verso regular son mayoritarios. Dice además Utrera: «Frente a la poética novísima más radical se alzan, como se vio en capítulos anteriores, varias voces defensoras de las formas tradicionales»(2001: 291), entre las que destaca la de Antonio Carvajal. Añade: «Los años setenta

\footnotetext{
${ }^{2}$ Las antologías son las siguientes: García Martín, José Luis (ed.), Treinta años de poesía española: (1975-1995). SevillaGranada: Editorial Renacimiento-La Veleta, 1996; García-Posada, Miguel (ed.), Poesía española, 10, La nueva poesía :(1975-1992). Barcelona: Crítica, 1996; Villena, Luis Antonio de (ed.), Fin de siglo. (El sesgo clásico en la última poesía española) Antología. Madrid: Visor, 1992; El último tercio de siglo, 1968-1998: antología consultada de la poesía española, [prólogo de José Carlos Mainer; introducción, Jesús García Sánchez; textos de Antonio Martínez Sarrión... (et al.)]. Madrid: Visor, 1998.
} 
conocen un resurgimiento de la métrica tradicional, como se aprecia en la obra de Luis Alberto de Cuenca, resurgimiento que se ve continuado claramente en la década de los ochenta, con Martínez Mesanza o Luis García Montero» (2001: 291). Teniendo en cuenta las fechas en las que comienza a escribir el poeta leonés (en 1969 se publican Poemas de la tierra y la sangre y Preludios a una noche total), vemos su clara afiliación con este tipo de actitudes que tienden hacia la vuelta a una métrica tradicional.

La métrica de Colinas es, sin embargo, de carácter más uniforme, sencilla y, sobre todo, menos experimental que la de otros poetas nombrados, como Carvajal, que se caracteriza por la utilización de estrofas y formas a veces ya casi olvidadas, o de complicada estructura.

Muy interesantes son los resultados obtenidos por Utrera Torremocha teniendo en cuenta, ya no los autores, sino la cantidad de poemas escritos en verso tradicional y en verso libre:

En resumen, teniendo en cuenta el total de poemas de las cuatro antologías, los resultados son los siguientes: sobre un $68 \%$ del total de los poemas sigue los moldes métricos regulares, aproximadamente un $12 \%$ responde al verso libre atenuado de base rítmica interrumpida y algo más de un $20 \%$ se ajusta a un verso libre más prosaico o que mezcla ritmos conocidos con un número amplio de versos claramente arrítmicos. A ello hay que añadir un grupo bastante escaso de poemas en prosa, además de otros experimentalismos poéticos minoritarios. (292).

Resulta muy interesante comparar estos porcentajes con los que nosotros hemos obtenido del estudio de la obra completa de Colinas hasta $2011^{3}$ y que presentamos en la siguiente tabla:

\footnotetext{
${ }^{3}$ Para este estudio nos hemos basado en la edición de la Obra poética completa de Antonio Colinas publicada por Siruela en 2011. Aunque posteriormente se ha publicado el poemario Canciones para una música silente (2014), y otros poemas inéditos recogidos en su reciente Lumbres (2016), por razones de unidad y coherencia hemos optado por el análisis de la obra completa recogida en el libro de Siruela de 2011.
} 
Tiempo de cambios, tiempo de tradición. La métrica de Antonio Colinas en su tiempo

\begin{tabular}{|c|c|c|c|c|c|}
\hline LIBROS & $\begin{array}{l}\text { Poemas de } \\
\text { regular }\end{array}$ & versificación & Poemas versoli & oristas & Otros \\
\hline & $\begin{array}{l}\text { Poemas en } \\
\text { Métrica } \\
\text { regular } \\
\text { isosilábica }\end{array}$ & $\begin{array}{l}\text { Poemas } \\
\text { regulares } \\
\text { por } \\
\text { combinación } \\
\text { de versos } \\
\text { (silvas y } \\
\text { otros) }\end{array}$ & $\begin{array}{l}\text { Poemas en } \\
\text { verso libre de } \\
\text { ritmo } \\
\text { endecasilábico }\end{array}$ & $\begin{array}{l}\text { Poemas en } \\
\text { verso libre } \\
\text { sin base } \\
\text { rítmica } \\
\text { tradicional }\end{array}$ & $\begin{array}{l}\text { Poemas } \\
\text { en prosa }\end{array}$ \\
\hline Junto al lago & 16 & - & - & - & - \\
\hline $\begin{array}{l}\text { Poemas de la tierra y } \\
\text { la sangre }\end{array}$ & 6 & - & - & - & - \\
\hline $\begin{array}{l}\text { Preludios a una noche } \\
\text { total }\end{array}$ & 29 & - & - & - & - \\
\hline $\begin{array}{l}\text { Truenos y flautas en } \\
\text { un templo }\end{array}$ & 17 & 1 & 12 & - & - \\
\hline Sepulcro en Tarquinia & 7 & 4 & 10 & - & - \\
\hline Astrolabio & 15 & 10 & 27 & - & - \\
\hline En lo oscuro & 1 & 6 & 2 & $y$ & - \\
\hline La viña salvaje & 30 & 3 & 4 & & - \\
\hline $\begin{array}{l}\text { Noche más allá de la } \\
\text { noche }\end{array}$ & 36 & & - & - & - \\
\hline Jardín de orfeo & 9 & 5 & 8 & 6 & 4 \\
\hline La muerte de armonía & 1 & - & - & - & - \\
\hline Los silencios de fuego & 10 & 5 & 10 & 5 & - \\
\hline $\begin{array}{l}\text { Libro de la } \\
\text { mansedumbre }\end{array}$ & 3 & 9 & 11 & 2 & - \\
\hline Tiempo y abismo & 4 & 10 & 30 & - & - \\
\hline Desiertos de la luz & 2 & 3 & 24 & 6 & - \\
\hline El laberinto invisible & 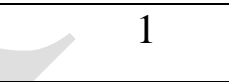 & 9 & 25 & 2 & - \\
\hline TOTAL & $187=42,8 \%$ & $65=14,9 \%$ & $163=37,3 \%$ & $21=5 \%$ & $4=0,9 \%$ \\
\hline
\end{tabular}

Aunque en algunos casos resulta muy complicado determinar con claridad a qué tipo de versificación pertenece un poema, hemos intentado tomar unos criterios claros. Para decidir qué poemas son isosilábicos no ha habido ninguna duda. El problema comienza con los poemas regulares por combinación de versos, que normalmente son silvas impares sin rima, o poemas en un determinado metro (endecasílabo, alejandrino) en los que se incluye algún verso esporádico en otro metro. La distinción, sin embargo, entre silvas impares regulares y versolibrismo de ritmo endecasilábico (lo que también podríamos llamar silva libre impar) es más complicada. El criterio que hemos utilizado es la existencia o no de versos con un número de sílabas par y mayores de cinco sílabas, caso en el que 
consideramos que ya hablamos de verso libre. Por otra parte, el criterio para distinguir los poemas libres de ritmo endecasilábico de aquellos sin base rítmica tradicional ha sido considerar qué número de versos responden a este ritmo endecasilábico; es decir, si más de la mitad de los versos eran endecasílabos, alejandrinos, heptasílabos o eneasílabos, hemos considerado que el poema era libre pero de ritmo endecasilábico; cuando esta condición no se cumplía hemos considerado que el poema era libre sin base rítmica tradicional.

Una vez explicado este punto podemos pasar a la comparación de los datos obtenidos en el estudio de Utrera Torremocha sobre las antologías citadas con los específicos que hemos recogido aquí de Antonio Colinas. En primer lugar podemos apreciar que los porcentajes entre uno y otro resultado no son tan diferentes. Utrera Torremocha cifraba en un $68 \%$ la influencia de la versificación regular, mientras que para Colinas el dato se reduce a un 57,7\% (la suma entre los regulares isosilábicos y por combinación de versos). Para el verso libre Utrera Torremocha cifra en un 32\% la incidencia total en sus antologías, mientras que para Colinas es algo mayor, un 42,3\%. El número de poemas en prosa es muy poco significativo. Así, podemos decir que nuestro poeta confirma, en líneas generales, las tendencias métricas actuales de versificación.

Hay, no obstante, un punto en el que los datos de Utrera Torremocha y los aquí presentados difieren significativamente; el que ella denomina como «verso libre atenuado de base rítmica interrumpida» (que podríamos asimilar a nuestro verso libre de ritmo endecasilábico) ${ }^{4}$ supone un $12 \%$ de los versos, mucho menos que el verso libre totalmente amétrico, que representa el $20 \%$ de las composiciones. Sin embargo, en Antonio Colinas las tendencias se invierten, y ese verso libre atenuado supone un 37,3\% de las composiciones, es decir, se convierte en una forma de versificar fundamental para el autor, especialmente en sus últimos poemarios. La tabla también deja ver lo que antes ya indicábamos acerca de la evolución métrica de Colinas contraria a la tendencia más general. En el poeta bañezano se aprecia claramente una evolución de la versificación regular a aquella libre atenuada y por último algunos poemas esporádicos en verso libre sin apenas relación con el ritmo endecasilábico.

Hay otro aspecto destacable en relación al verso libre extenso o versículo ${ }^{5}$, del que comenta Utrera Torremocha: «Más de la mitad de los poemas escritos en verso libre, sean con ritmos prosaicos o de base métrica, prescinden del versículo» (2001: 293). En Colinas no es, sin embargo, extraño

\footnotetext{
${ }^{4}$ Es difícil saber con exactitud dónde pone el límite Utrera Torremocha para hablar de verso libre prosaico o arrítmico y de «verso libre atenuado».

${ }^{5}$ En el Diccionario de métrica española de José Domínguez Caparrós encontramos como primera entrada para Versículo «verso libre» (2007), y como sinónimo de este tipo de versificación ha sido utilizado con frecuencia. En otra publicación especifica: «El verso libre, o versículo, que prescinde normalmente de la rima y cuyas líneas no se ajustan frecuentemente a la acentuación de los metros regulares, se puede constituir como verso libre medio [...] o mayor» (2000: 188). Varela, Moíño y Jauralde, definen el versículo casi exclusivamente por su extensión: «de más de dieciséis sílabas, por lo general; o si se prefiere: de más de seis a ocho acentos de intensidad. Se le reconoce por dos cosas: la presencia inequívoca de un límite (el final de verso) y las asociaciones que establece con unidades semejantes con las que se ha formado la poesía en verso» (2005: 37). Isabel Paraíso, sin embargo, se muestra contraria a estas acepciones: «Tanto Amado Alonso como S. Gili Gaya o C. Bousoño identifican sin más "versículo" y "verso libre”. Por nuestra parte, basándonos en la práctica del francés ("verset") y en el origen bíblico del versículo, consideramos a éste como una forma de verso libre basada en el paralelismo y con medidas mayoritariamente extensas» (1985: 29).
} 
encontrar versos mayores de las catorce sílabas dentro de sus poemas versolibristas. Este tipo de versos casi nunca son la base del poema, sino que resultan ocasionales.

Interesante es también que, incluso dentro del porcentaje de poemas escritos en verso libre amétrico, la autora puntualiza: «Muchas de las composiciones consideradas como escritas en verso libre responden a menudo a los esquemas regulares subvertidos en mayor o menor medida» (2001: 293). También Martínez Fernández destaca esta característica al hablar de la «desarticulación de estrofas canónicas» (1996: 98-110). Así, vemos una vez más cómo la distinción entre tipos de verso libre según su relación con la métrica tradicional es más intrincada de lo que podría parecer a primera vista.

\section{Colinas y los Novísimos}

Un campo ya suficientemente estudiado ha sido el de la adscripción o no del poeta leonés a este grupo poético reunido en la antología de Castellet. Aquí no se pretende volver sobre tal polémica, sino que simplemente nos centraremos en los aspectos métricos de este grupo y en su comparación con la métrica de nuestro autor.

Las elecciones sobre la forma métrica de su poesía primera tendrían para Colinas grandes consecuencias en el campo de la cultura. La adhesión a la métrica tradicional tan férrea de su primera obra le valió la exclusión de la antología que daría nombre y fama a los poetas de su grupo generacional: Nueve Novísimos Poetas Españoles, reunida por Castellet en 1970. Las razones de esta decisión las explica en una entrevista uno de los escritores que sí recoge la citada antología, Gimferrer:

[...] debo decir que si Antonio Colinas no fue incluido se debió simplemente a que José María [Castellet] estimaba que era un excelente poeta pero demasiado clásico en comparación con los demás. Yo tuve que respetar en ese caso la opinión del antólogo aunque no la compartía (García de la Concha, 1989: 28).

Ruiz Casanova comenta también esta decisión de la exclusión del escritor bañezano de la antología: «un Antonio Colinas al que entonces estimó - y con razón- escasamente sintomático de una sensibilidad distinta y más o menos común a los seleccionados» (1990: XVIII). En realidad Colinas sí distaba mucho de la poesía de los Novísimos, lo que no significa que expresara una sensibilidad diferente a todas las tendencias del momento.

Para la antología de Castellet se seleccionaron poetas y composiciones que resultaban expresamente diferentes de la poesía del momento, sobre todo de la poesía social, en sus temas y en sus formas: «La antología no pretendía dar una muestra representativa de la producción poética joven en España a fines de los años sesenta, sino tan sólo mostrar una parte de ésta: aquella caracterizada por su voluntad de rupturista con el realismo precedente» (Lanz, 2001: 17). Así, una de las características del grupo que enunciaba el propio Castellet era precisamente la «despreocupación hacia las formas tradicionales»: 
Ésta es una característica obvia: la libertad formal es absoluta y, en líneas generales, no hay ninguna preocupación preceptiva. De todos modos, hay que señalar — como excepción — el ritmo verbal basado en la tradición métrica castellana empleado por Gimferrer, especialmente, y por Carnero (Castellet, 2001: 41).

Vemos así que lo predominante en Nueve novísimos es el versolibrismo, con algunas excepciones por parte de autores que luego han sido fundamentales en la trayectoria de la poesía última española ${ }^{6}$. También Santiago Martínez destaca entre las características formales de la antología la siguiente: «una mezcla de prosa y verso al margen de elementos rítmicos o de cualquier formalismo insertable en la tradición» (1990: X).

Este es uno de los puntos en los que Colinas más se distanció de ese grupo poético. Como se ha ido viendo, en el poeta leonés existe una gran preocupación por todos los aspectos del poema, entre ellos la forma métrica. Su clasicismo primero pudo jugar inicialmente en su contra, pero a la postre actuó como una garantía de calidad rítmica del poema ${ }^{7}$.

Otra de las características relacionadas con el ritmo que atribuye al grupo novísimo el crítico catalán es la de «escritura automática, técnicas elípticas, de sincopación y de "collage"» (Castellet, 2001: 41). Argumenta que ello es debido a que «se trata de evitar el discurso lógico, de romper la expresión silogística, para crear, en algunos casos, una "ilógica razonada" y, en otros, un "campo alógico" significante, cuya lectura exige un esfuerzo más visual que racional» (2001: 41). Los elementos visuales de la poesía de Antonio Colinas no son muchos, y, desde luego, no funcionan como base de sus poemas. La búsqueda de la irracionalidad tampoco se presenta como una característica típica de la lírica del autor ${ }^{8}$. Pilar Yagüe, refiriéndose concretamente a Astrolabio, nos da una percepción de esta obra que puede ser válida para toda la obra del poeta leonés: «la poesía de Colinas, a diferencia de gran parte de la de sus compañeros de generación, no remite a un universo fragmentado, inconexo» (1997: 174). A ello contribuyen los moldes métricos clásicos, que se alejan del fragmentarismo del verso libre más liberado, que además suele llevar ciertas marcas gráficas que acentúan esta incompletitud temática y formal.

Sin embargo, hay que decir que aunque siempre se ha distanciado a Colinas del grupo de los Novísimos, él mismo, a pesar de su clasicismo métrico, entiende y defiende las innovaciones métricas que este grupo introdujo, y según su propio criterio no son éstas, de hecho, las que le separan más de los poetas de esta generación:

Las generaciones literarias a veces tienen razón de ser, son útiles por razones didácticas, pero para nada más. Cada poeta tiene su voz, su personalidad, y a la larga, yo creo que sólo existen poetas independientes. Qué duda cabe que yo estoy en la órbita de eso que se ha venido a llamar poesía novísima. Una poesía con la que yo estoy de acuerdo con lo que supuso de renovación respecto al lenguaje, de ruptura

\footnotetext{
${ }^{6}$ Así, los primeros textos de Gimferrer, Malienus (no publicado hasta 1988) y Mensaje del Tetrarca, de 1963, se basan en series de endecasílabos y alejandrinos (con hemistiquios además muy marcados) y generalmente con rima asonante en los pares.

${ }^{7}$ En esta misma línea afirma Amorós refiriéndose a los Novísimos: «Eran tan actuales (entonces), tan modernos, que no es raro que ahora empiecen a parecer antiquísimos. Conviene no olvidar que lo clásico no está nunca del todo de moda, pero tampoco acaba de pasarse» (1989: 63).

${ }^{8}$ Argumenta Susana Agustín: «Por su parte, los poemas de Colinas no requieren ningún esfuerzo lógico y racional añadidos: se trata de poemas, ya narrativos, ya descriptivos, con una clara consecución lógica. Poseen un punto del que arrancan y en torno al cual el poeta hilvana las ideas que con lógica se exponen en el poema» (2011: 87).
} 
con las ataduras que existía con la poesía demasiado tradicional. Todo esto es interesante, pero por lo demás, no me identifico con este grupo que ejerció la cultura por la cultura, en el que había poco sustrato vital en ella. Luego había cosas muy puntuales, como que yo era bastante fiel a Machado cuando los Novísimos lo criticaron mucho. Temas como la presencia de la naturaleza que en mi obra es un factor dinamizador, vital, está como telón de fondo, como un elemento cultural más. En este grupo la poesía tiende a lo urbano. Para mí la diferencia está en el concepto de la cultura. Ha sido reconocida como generación novísima o culturalista, y para mí si en la cultura no hay vida, no es tal cultura. Las referencias culturales en mi obra siempre remiten a experiencias vitales, no se da esa presencia de la cultura por la cultura (Delgado, 2002).

Muchas han sido las polémicas, de todas maneras, en torno a la consideración de los Novísimos como generación, grupo poético, etc., e incluso respecto a su denominación ${ }^{9}$. Después de todo, el propio José María Castellet reconoció en una reunión a raíz de los treinta años cumplidos por la antología: «Nunca fuisteis un grupo poético sino un grupo intelectual y cultural que después de tantos años representáis algo en el complejo mundo cultural español» (Maurell, 2001).

El propio Antonio Colinas es también, pese a su clasicismo, un gran innovador en su época. De hecho, su poema «Sepulcro en Tarquinia» resultó en su momento muy innovador por su carácter y por su tamaño en una época en la que se tendía a las composiciones breves (Rozas 1989: 1). Así lo manifiesta también Pilar Yagüe:

Una marca distintiva no obstante, singulariza de nuevo a Colinas respecto de otros poetas: en una época en que se está comenzando a imponer una retórica de la supresión y se escriben cada vez poemas más cortos, el poema «Sepulcro en Tarquinia», que da título al libro, tiene alrededor de cuatrocientos versos (1997: 146).

Esta fórmula del poema-río extenso la volverá a repetir el poeta bañezano en «La tumba negra» (471 versos), del Libro de la mansedumbre, publicado en 1997. Más recientemente, en Canciones para una música silente incluyó también «El soñador de espigas lejanas», un poema de 238 versos. El hecho de encontrarse composiciones tan largas sorprende todavía en nuestros días. Así, Fuente de Médicis, de Guillermo Carnero publicado recientemente, en 2006, presenta también la forma de un poema extenso $^{10}$, a lo que Díez de Revenga dice: «pone de relieve que el poema extenso, el poema muy extenso, tan ausente hoy de nuestras letras, tiene su razón y sentido como lo tuvo en las épocas más áureas de nuestras letras» (2008: 24).

Otros elementos ponen en común el poema-libro de Carnero y los de Colinas, como las influencias de Hölderlin, Aleixandre, Cernuda, etc., pero también el asunto que aquí nos interesa, es decir, la métrica: «Espléndidos endecasílabos, majestuosos alejandrinos y necesarios heptasílabos consagran una andadura poética nobilísima, que dota al poema de un ritmo sereno, reflexivo y

\footnotetext{
${ }^{9}$ García Berrio afirma que prácticamente no hay ningún elemento que permita «fácilmente encontrar el denominador común de su estética, que los aglutine como grupo generacional o al menos como escuela poética» (1989: 13), si bien propone que este elemento común sea el imaginario cultural. En el mismo sentido se pronuncia años más tarde Antonio Gracia: «En puridad, no tienen en común, como generación, más que el hecho de habérseles buscado un denominador común» (1997: 18). Por otra parte, Barnatán hace referencia a los múltiples nombres que se han dado a estos poetas: venecianos en un primer momento, Novísimos a partir de la aparición de la antología de Castellet, generación del lenguaje para Carlos Bousoño o generación del 68 ó 70 para algunos antólogos y críticos (1989: 16).

${ }^{10}$ También el libro anterior de este autor, Espejo de gran niebla, publicado en 2002, se compone de poemas extensos, pero no tanto, en torno al centenar de versos cada uno.
} 
acogedor» (Díez de Revenga, 2008: 24). La utilización, tanto en este libro como en anteriores de este autor, de la silva libre impar será muy común.

Vemos así que Antonio Colinas no se sitúa fuera de los cánones métricos actuales, y, aunque no pretende una ruptura con lo anterior, no rechaza las posibles innovaciones que más allá de ser algo sólo formal, le abran un nuevo camino a la significación.

\section{Entre el clasicismo métrico y la innovación}

La también poeta Amparo Amorós trata de sintetizar en un artículo de 1989 las corrientes poéticas españolas que desde los Novísimos había habido. No se olvida de hacer referencia, eso sí, bastante breve y necesariamente vaga, a la métrica en un epígrafe llamado «La vuelta a las formas métricas clásicas»:

\footnotetext{
Con el poderoso antecedente en la Generación del 70 de la obra del granadino Antonio Carvajal, los poetas, en esta última década, parecen interesarse de nuevo por el uso de las formas métricas tradicionales, en rimas y estrofas clásicas. Con diferentes usos y matices, que van desde el pastiche internacional (Juaristi), a formalismo depurado (Francisco Castaño, Isabel Abad, Jaime Siles), pasando por el lirismo finamente frío y renovador de Justo Navarro, o la decidida y confesada imitatio de Fernando Villena, o mi intento de actualizar y trasgredir una forma métrica (el soneto) con fines satíricos en mi último libro (Quevediana, 1988), resulta evidente que la poesía no quiere privarse de placeres y posibilidades formales tan legítimos, y, para bien, los saca del baúl de los recuerdos, sirviéndolos con mimo o perdiéndoles el respeto, para jugar con ellos, como cumple a los buenos gozadores de la palabra. Y a quienes hablan de arqueología y lanzan venablos contra este rescate de la métrica, tachándola de manida y codificada, no vendría mal recordarles que el verso libre o versículo están, a estas alturas, igualmente maltrechos y ajados, y, cuando son flojos, producen el mismo tedio, si no más. (1989: 67)
}

También Julia Barella recoge en un artículo las nuevas tendencias poéticas que se dejan entrever desde los Novísimos hasta los años noventa, y señala una nueva tendencia poética en la que incluye a escritores como Luis Alberto de Cuenca, Abelardo Linares, Jon Juaristi, Miguel d'Ors, Luis García Montero, Felipe Benítez, etc. (lo que se ha venido llamando «poesía de la experiencia»). Habla de ciertos cambios entre los que destaca «la vuelta a los metros clásicos y a la rima» (1998: 16).

La evolución métrica del poeta aquí estudiado, Antonio Colinas, que queda reflejada de una manera bastante fiel en el cuadro recogido en este artículo. Es un tipo de métrica que no se ciñe exactamente a la tónica general de la poesía española de los últimos años. Así, comienza haciendo uso de una métrica totalmente clásica a principios de los 70 , ciñendo su obra a poemas isosilábicos en endecasílabos y alejandrinos sin rima, yendo en contra de una tendencia generalizada en esos años hacia el verso libre. En la década de los 80, cuando otros poetas apuestan decididamente por una vuelta a los patrones métricos clásicos, Antonio Colinas comienza a renovar su métrica y a escribir mayoritariamente en verso libre, si bien un tipo de verso libre que se liga fuertemente a la métrica de tipo tradicional. Realiza, además, algunas experimentaciones métricas con versículos y con el poema en prosa. De este modo, el poeta leonés parece apoyarse en una primera época de su producción poética en la seguridad estética y rítmica que le proporcionan los versos clásicos, y a partir de ellos comienza 
Tiempo de cambios, tiempo de tradición. La métrica de Antonio Colinas en su tiempo

a introducir otras sonoridades compatibles. Así, gran parte de sus poemas podríamos decir que están escritos en un tipo de 'versolibrismo clásico'.

Será este verso libre de clara base endecasilábica el que caracteriza de forma general la poesía del escritor ${ }^{11}$. La versificación de Antonio Colinas, tanto regular como libre, se define por su clasicismo, su fondo rítmico fácilmente perceptible y por una forma de entender la innovación como algo siempre ligado a la tradición. Este tipo de métrica, junto con los temas tratados y la calidad de sus poemas, se configuran como claves del éxito de su obra, unida siempre a un ritmo claro, a una segura musicalidad.

\section{Bibliografía}

Agustín Fernández, S. (2004): Poesía y pensamiento en Antonio Colinas (1967-1988). Tesis Doctoral leída en 2004, en http://eprints.ucm.es/9489/ (última consulta, 1-8-2017).

Amorós, A. (1989): «iLos Novísimos y cierra España!: reflexión crítica sobre algunos fenómenos estéticos que configuran la poesía de los años ochenta», Insula: revista de letras y ciencias humanas, 512-513, pp. 63-67.

Barella Vigal, J. (1998): «De los Novísimos a la poesía de los 90», Clarín: Revista de nueva literatura, 15, pp. 13-18.

BARNATÁN, M-R. (1989): «La polémica de Venecia», Insula: revista de letras y ciencias humanas, 508, pp. 15-16.

CAStellet, José María (2001): Nueve Novísimos poetas españoles. Barcelona, Península, 1ª ed., 1970.

ColinAS, A. (2011): Obra poética completa. Madrid, Siruela.

(2014): Canciones para una música silente. Madrid, Siruela.

(2016): Lumbres, Ed. de Sánchez-Perez y A. Sánchez Zamarreño. Salamanca, Ediciones Universidad de Salamanca y Patrimonio Nacional.

Delgado Batista, Y. (2002), «Antonio Colinas o el poeta tranquilo. Entrevista a Antonio Colinas», Espéculo: Revista de Estudios Literarios 20.

DíEz de Revenga, Fco. J. (2008): «Permanencia de los Novísimos», Monteagudo: Revista de literatura española, hispanoamericana y teoría de la literatura, 13, pp. 15-24.

DOMínguez CAPARRós (2000): Métrica española. Madrid, Síntesis, $1^{\text {a }}$ ed., 1993.

(2007): Diccionario de métrica española. Madrid, Alianza, $1^{\text {a }}$ ed., 1985.

GARCÍA BERRIO, A. (1989). «El imaginario cultural en la estética de los "Novísimos”», Insula: revista de letras y ciencias humanas, 508, pp.13-15.

GARCÍA DE LA CONCHA, V. (1989). «Entrevista a Pere Gimferrer», Insula: revista de letras y ciencias humanas, 505, pp. 28.

\footnotetext{
${ }^{11}$ Cabe citar ciertas excepciones en su obra que se aferran a la métrica regular, como sus primeros poemarios y, sobre todo, Noche más allá de la noche, publicado en 1983, y que está compuesto por treinta y cinco cantos y un post-scriptum escritos todos ellos en alejandrinos.
} 
GRACIA, A. (1997): «Una revisión de los “Novísimos”», Insula: revista de letras y ciencias humanas, 607, pp.16-18.

LANZ, J. J. (2001): «Prolegómenos para una lectura: nueve Novísimos, treinta años después», Insula: revista de letras y ciencias humanas, 652, pp. 13-20.

MartíneZ, S. (1990): «Nueve Novísimos: una antología, un nombre», Anthropos: Boletín de información y documentación, 110-111, pp. VIII-XIV.

Martínez Cantón, C. I. (2011): Métrica de Antonio Colinas. Sevilla, Padilla Libros. (2012): El ritmo como clave del verso en Antonio Colinas. Elementos rítmicos no métricos. León, Universidad de León.

MARTínez FERnÁndEZ, J. E. (1988): «La belleza conseguida en los dos nuevos libros de Antonio Colinas», Lirba 13 y 14, Abril-Agosto de 1988, pp. 33-36.

(1990): «En torno a la poética de Antonio Colinas», Lirba,17, Septiembre de 1990, pp. 38-41. (1996): El fragmentarismo poético contemporáneo. León, Universidad de León.

(1997): «La voz del Renacimiento en la obra de Antonio Colinas: Tradición y actualidad», en A. Colinas et alii, El viaje hacia el centro [La poesía de Antonio Colinas]. Calambur, Madrid, pp. 91-102.

(1998): «La recepción del Renacimiento en la obra de Antonio Colinas», en J. MATAS, J. M. Trabado, M. L. González y M. PARAmio, coords., Actas Congreso Internacional sobre Humanismo y Renacimiento, vol. II, Universidad de León, León, pp. 487-494.

(2004a): «Introducción y notas», en Antonio Colinas, En la luz respirada (Sepulcro en Tarquinia, Noche más allá de la noche, Libro de la mansedumbre). Cátedra, Madrid.

- (2004b): «Armonía y ritmo en Antonio Colinas: ajustes métricos en Noche más allá de la noche», Rhythmica. Revista Española de Métrica Comparada, 2, Sevilla, 2004, pp. 137-158.

- (2008a): «Poética del cuadro ausente. Poesía y pintura en Antonio Colinas», Signa, 17, pp. 225 248.

(2008b): «Lecturas interesadas del Quijote (los casos de José María Merino y Antonio Colinas)», en M. A. Garrido Gallardo y L. Alburquerque, coords., El Quijote y el pensamiento teórico-literario. Madrid, CSIC, pp. 331-340.

(2009): «Donde Orfeo nos espera con sus acordes. El pensamiento poético de Antonio Colinas», en T. Blesa, J. C. Pueo, A. Saldaña y E. Sullá, eds., Pensamiento literario español del siglo XX, 3, Anexos de Tropelías, Universidad de Zaragoza, pp. 89-112.

(2010):«Antonio Colinas: La isla y su simbología», en J. J. LANERo, J. L. ChAMOSA, eds., Lengua, traducción, recepción. En honor de Julio César Santoyo, vol. II. León, Universidad de León, pp. 283-314.

(2012): «Obra poética completa, de Antonio Colinas», Ínsula, 792, pp. 24-27.

(2014): «La dialéctica dentro-fuera en la poesía de Antonio Colinas», en Francisco Aroca Iniesta, coord., Leer la obra de Antonio Colinas. París, Indigo / Centre d’Études Hispaniques d'Amiens, pp. 253-267. 
Tiempo de cambios, tiempo de tradición. La métrica de Antonio Colinas en su tiempo

Martínez FernándeZ, J. E. - MARTínez CANTÓN, C. I. (2007): «Oscuro oboe de bruma... Métrica, ritmo e interpretación», Rhythmica. Revista Española de Métrica Comparada, 3-4, pp. 181-194.

Maurell, P. (2001): «Nueve Novísimos, treinta años después», El Mundo, 6 de marzo de 2001.

Navarro Tomás, T. (1991): Métrica española. Barcelona, Labor, $1^{\mathrm{a}}$ ed., 1956.

PARAísO, I. (1985): El verso libre hispánico: orígenes y corrientes. Madrid, Gredos.

RoZAS, J. M. (1989): «Mi visión del poema "Sepulcro en Tarquinia"», Insula: revista de letras y ciencias humanas, 508, pp.1-2.

Ruiz Casanova, J. Fco. (1990): «Nueve Novísimos: ¿la última generación poética española?», Anthropos: Boletín de información y documentación (Ejemplar dedicado a: Juan Gil-Albert), 110-11, pp. XIV-XVII.

Utrera TORREMOCHA, $\mathrm{M}^{\mathrm{a}}$ V. (2001): Historia y teoría del verso libre. Sevilla, Padilla Libros.

VARela, E. - Moíño, P. - Jauralde Pou, P. (2005): Métrica española. Madrid, Castalia.

Yagǘ LóPEZ, P. (1997): La poesía en los setenta: los «Novísimos», referencia de una época. La Coruña, Universidade da Coruña. 